\title{
Tendon Derived Stem Cells Promote Platelet-Rich Plasma Healing in Collagenase-Induced Rat Achilles Tendinopathy
}

\author{
Lei Chen ${ }^{\mathrm{a}}$ Jun-Peng Liu ${ }^{\mathrm{b}}$ Kang-Lai Tang ${ }^{\mathrm{b}}$ Qing Wang ${ }^{\mathrm{a}}$ Guo-Dong Wang ${ }^{\mathrm{a}}$ \\ Xian-Hua Cai ${ }^{a}$ Xi-Ming Liu ${ }^{a}$ \\ aDepartment of Orthopaedics, Wuhan General Hospital of Guangzhou Military Region, Wuhan, \\ 'Department of Orthopaedics, Southwest Hospital, Third Military Medical University, Chongqing, China
}

\section{Key Words}

Tendinopathy $\bullet$ Tendon derived stem cells $\bullet$ Platelet rich plasma $\bullet$ Collagen

\begin{abstract}
Background/Aims: Tendon injuries are common, difficult to cure and usually healed with fibrosis and scar tissue. The aim of this study was to evaluate tendon derived stem cells (TDSCs) and platelet rich plasma (PRP) in the treatment of collagenase induced Achilles tendinopathy in rat. Methods: Four and 8 weeks $(n=18)$ after TDSCs, PRP, PRP with TDSC or PBS (control) injection into collagenase or saline (sham) injected rat Achilles tendon, tendon tissue was harvested and tendon quality was evaluated by histology and biomechanical testing. TDSCs were cultured and treated by $10 \%$ PRP, and the FAK/ERK1/2 signaling pathway and tenocyterelated genes were detected by western blot analysis. Results: Compared to the control, PRP treatment resulted in better healing of injured tendons with improved histological outcomes and biomechanical functions. The addition of TDSCs to PRP treatment significantly enhanced the effects of PRP treatment alone. TDSC injection alone had little effect on tendon healing. PRP and PRP with TDSC treatments of collagenase induced tendon injuries also increased the mRNA and protein expression of tenocyte-related genes (type I collagen, SCX, Tenascin C) and activated the focal adhesion kinase (FAK) and extracellular-regulated kinase (ERK) 1/2 signaling pathways. Treatment of TDSCs in vitro with $10 \%$ PRP significantly increased the phosphorylation levels of FAK and ERK1/2 and the protein levels of tenocyte-related genes (Col I, SCX and Tenascin C). Inhibition of the FAK and ERK1/2 signaling pathways abolished the effect of PRP. Conclusion: This study concludes that PRP combined with TDSCs is potentially effective for the treatment of tendinopathy. The PRP induced, FAK and ERK1/2 dependent activation of tenocyte related genes in TDSCs in vitro suggests that the beneficial healing effect of the PRP with TDSC combination might occur by means of an improved TDSC differentiation toward the tenocyte lineage. Thus, a PRP with TDSC combination therapy may be clinically useful.

Copyright (C) 2014 S. Karger AG, Basel

Xian-Hua Cai

or Xi-Ming Liu

Department of Orthopaedics, Wuhan General Hospital of Guangzhou Military Region Mail code 430070, Wuhan (China)

Tel. 086-27-68879519, E-Mail caixianhuakxy@126.com or E-Mail liuximingkxy@126.com
\end{abstract}




\section{Cellular Physiology and Biochemistry}

Cell Physiol Biochem 2014;34:2153-2168

Chen et al: TDSCs Promote PRP Induced Healing in Achilles Tendinopathy

\section{Introduction}

Tendon injury is a common problem in sports medicine and orthopedic practice and gives rise to significant tendon tissue morbidity. Tendon is composed of tendon cells (tenocytes) and their immature precursors (tenoblasts), which lie within a network of extracellular matrix. Tenocytes synthesize collagen and all components of the extracellular matrix [1]. Tendinopathy has been characterized histologically by disordered haphazard healing with the absence of inflammatory cells, a poor healing response, non-inflammatory intratendinous collagen degeneration, fiber disorientation and thinning, hyper cellularity, scattered vascular ingrowth and increased interfibrillar glycosaminoglycans [1]. Novel treatment approaches, including tissue engineering and the local delivery of growth factors, aim to mimic the micro-environment that may be necessary to provide cells with the cues to develop into tendo-/ligamentocytes [2].

A wide range of donor cell types have been used to promote tendon healing in pre-clinical studies, including bone marrow-derived mesenchymal stem cells (BMSCs) [3-5], periodontal ligament or gingival tissue [6], dermal fibroblast [7], tenocytes [8], peripheral blood-derived MSCs [9, 10] and embryonic stem cell derived MSCs (ESC-MSCs) [11]. Each cell source has its limitations including inferior proliferation, differentiation and collagen production abilities of tenocytes [12-15], risk of teratoma formation of ESCs as well as risk of ectopic bone [3] and tumor induction [16] of BMSCs when using a certain scaffold. For this reason, lineage direction of stem cells is recommended prior to their use in cell-based therapies [9, 10]. Recently, the more lineage committed tendon derived stem cells (TDSCs), also called tendon stem/progenitor cells, have been identified in a number of species [17-20]. TDSCs have the potential to differentiate into several cell types, including tenocytes, adipocytes, chondrocytes and osteocytes. Compared to BMSCs, TDSCs highly express tenocyte related markers including scleraxis (Scx), tenomodulin and tenascin-c $[17,21]$. When injected into mice, TDSCs were more likely to form tendon unlike BMSCs, which preferentially formed bone $[17,19]$. The reparative potential of TDSCs was recently demonstrated by $\mathrm{Ni}$ and colleagues who showed that TDSCs promoted tendon repair in a rat patellar tendon window defect model [22]. Given the limited availability and morbidity in harvesting autologous tendon tissue for grafts, the clonogenicity, multipotency and self-renewal capacity of TDSCs make them an attractive source of bankable material for allogenic transplantation in tendon repair. However, the negative side effects of allogenic stem cell transplantation, such as the risk of infection and immune rejection, must be considered.

Platelet-rich plasma (PRP) is an autologous source of concentrated platelets containing growth factors such as platelet-derived growth factor (PDGF), transforming growth factorbeta1 (TGF- $\beta 1$ ), vascular endothelial growth factor (VEGF), epidermal growth factor (EGF) and insulin-like growth factor (IGF-1) that stimulate tissue healing $[23,24]$. The expression of many of these factors, such as IGF-I and TGF- $\beta 1$, are increased in tendons during healing making PRP an attractive therapeutic strategy for tendon regeneration [25, 26]. Treatment of tendons with active releasate of PRP (platelet-rich clot releasate [PRCR]) can increase tenocyte numbers and the production of collagen types I and III, the main components of tendons $[27,28]$. In vitro, PRCR stimulates the differentiation of TDSCs into active tenocytes [29] and inhibits TDSC differentiation towards non-tenocyte lineages that are known to impede healing [21]. Autologous PRP is advantageous for use in patients because it eliminates concerns about immune responses and disease transmission. The safe use of allogenic PRP has also been reported [9, 10]. Pre-clinical studies using autologous PRP to promote the healing of tendons or ligaments have shown promising results [30-33]. Although initial clinical trials have demonstrated limited efficacy [31, 34-38], improvements in technique and PRP makeup warrant further studies.

A number of molecular pathways that control the differentiation of tendon stem cells into tenocyte and non-tenocyte lineages have been reported. The tendon stem cell niche is thought to control stem cell fate in part by modulating bone morphogenetic protein (BMP) activity, which inhibits tendon formation in chick and mouse development [39]. The extracellular 


\section{Cellular Physiology and Biochemistry}

Cell Physiol Biochem 2014;34:2153-2168

\begin{tabular}{l|l}
\hline DOI: $10.1159 / 000369659$ & (C) 2014 S. Karger AG, Basel
\end{tabular}

www.karger.com/cpb

Chen et al.: TDSCs Promote PRP Induced Healing in Achilles Tendinopathy

matrix proteins biglycan (Bgn) and fibromodulin (Fmod) are critical components of the tendon stem cell niche because in their absence, tendon stem/progenitor cells display increased sensitivity to BMP2 $[17,39]$. More is known about tenocyte differentiation from in vitro studies with TDSCs and MSCs. PRCR promotes TDSC differentiation into tenocytes and inhibits non-tenocyte lineagesin rat and rabbit [21, 29], whereas BMP-2 differentiates TDSCs along non-tenocyte pathways in rat [40]. The identity of the PRCR factors that stimulate TDSC differentiation into tenocytes remains to be determined. Human MSCs differentiate alongthe tenocyte lineage by the activation of the RhoA/Rock and FAK signaling pathways $[41,42]$ and murine MSCs differentiate alongtenocyte lineages by the combined activation of BMP-2 and Smad8 signaling [43].

In this study we explored the use of TDSCs for tendon repair in the collagenase induced Achilles tendon injury rat model [44]. We also tested TDSCs combined with PRP, given PRP's ability to promote tenocyte differentiation of TDSCs in vitro [21, 29].

\section{Materials and Methods}

Animals

Eight-week-old Sprague-Dawley male rats, weighing 250-300 g, were used in the study. All animals were treated according to institutional guidelines for laboratory animal treatment and care. All experiments were approved by the Animal Research Ethics Committee, Third Military Medical University, China (Approval No. SYXK-PLA-20120031).

\section{Preparation of platelet rich plasma}

PRP was prepared from three rats, which were then euthanized for TDSC isolation. As described previously [45, 46], $20 \mathrm{ml}$ of carotid artery blood was obtained from each rat using a syringe containing $2 \mathrm{ml}$ anticoagulant (acid citrate dextrose). A total of $60 \mathrm{ml}$ of whole blood was centrifuged at $200 \mathrm{~g}$ for 10 min followed by $1,200 \mathrm{~g}$ for $10 \mathrm{~min}$. The precipitated platelets at the bottom of the centrifuge tube were resuspended in $1 \mathrm{ml}$ of the supernatant (platelet-poor plasma) to yield PRP. A platelet count was obtained for whole blood and PRP (all measurements were performed by FALCO, Japan). Purified PRP platelet concentration was adjusted to $1.766 \times 10^{6}$ platelets $/ \mu$. To examine the concentrations of growth factors in the PRP, we measured the concentrations of TGF- $\beta 1$ and PDGF-BB in whole blood and PRP by enzymelinked immunosorbent assay (ELISA) using a TGF- $\beta 1$ and PDGF-BB ELISA Kit (R\&D Systems, Minneapolis, MN, USA) according to themanufacturer's instructions.

Isolation and culture of tendon derived stem cells

TDSCs were isolated and cultured as previously described [21, 45]. Briefly, hind limb Achilles tendons dissected from euthanized rats were washed twice in DPBS, transferred to a $35 \mathrm{~mm}$ dish, minced into fine pieces $\left(1 \mathrm{~mm}^{3}\right)$ and digested with $3 \mathrm{mg} / \mathrm{ml}$ collagenase I (Sigma-Aldrich Co. Ltd., St. Louis, MO, USA) and $4 \mathrm{mg} / \mathrm{ml}$ dispase (Sigma-Aldrich) in $500 \mu \mathrm{l}$ phosphate buffered saline (PBS; $0.01 \mathrm{M}$, pH 7.4) at 37응 for 1 h. After stopping the digestion with $5 \mathrm{ml}$ PBS and removing undigested tissues with a 200 mesh filter, the resulting suspension was centrifuged at $600 \mathrm{~g}$ for $5 \mathrm{~min}$. The cells wereresuspended in DMEM supplemented with $20 \% \mathrm{FBS}$ and $100 \mu \mathrm{M}$ mercaptoethanol (Sigma-Aldrich), and cultured in a $0.1 \%$ gelatin-coated $35 \mathrm{~mm}$ dish. The medium was changed 5 and 8 days after plating. After 8-10 days in culture, tendon-derived cells formed adherent colonies, which were subcultured in new tissue culture dishes for up to two passages to a cell density of 5,000-8,000 cells/ $\mathrm{cm}^{2}$ to obtain sufficient numbers. At the third passage, tendon-derived cells were evaluated for the presence of stem cell markers by flow cytometry and were CD44(+)/CD90(+)/ CD34(-)/CD45(-).

Flow cytometry assay

Tendon-derived cells $\left(5 \times 10^{5}\right)$ were incubated with $1 \mathrm{mg}$ of phycoerythrin-conjugated or fluoresceinisothiocyanate-conjugated mouse anti-rat monoclonal antibodies (R\&D Systems) for $1 \mathrm{~h}$ at $4^{\circ} \mathrm{C}$. The antibodies used in this study were anti-CD44 and anti-CD90 (Abcam, Cambridge, MA, USA); anti-CD34 


\section{Cellular Physiology and Biochemistry}

Cell Physiol Biochem 2014;34:2153-2168

\begin{tabular}{l|l}
\hline DOI: $10.1159 / 000369659$ & (C) 2014 S. Karger AG, Basel
\end{tabular}

www.karger.com/cpb

Chen et al.: TDSCs Promote PRP Induced Healing in Achilles Tendinopathy

and anti-CD45 (Santa Cruz Biotechnology, Santa Cruz, CA, USA). They were replaced with phycoerythrinconjugated or fluorescein-isothiocyanate-conjugated isotype-matched IgG1 in negative controls. The stained cells were washed with PBS at $400 \mathrm{~g}$ for $5 \mathrm{~min}$ then re-suspended in $500 \mu \mathrm{l}$ of ice-cold PBS (with $10 \%$ fetal bovine serum and 1\% sodium azide) and subjected to FACS analysis (Becton Dickinson, Franklin Lakes, NJ, USA). About $10^{4}$ events were counted for each sample. The percentage of cells with positive signal was calculated using the FACSCAN program (Becton Dickinson, San Jose, CA, USA).

\section{Animal study design}

Rats were randomly allocated into the following five treatment groups of 24: (1) PRP, (2) TDSCs, (3) PRP with TDSCs (4) control (the injury model control) and (5) sham group (a normal tendon control). Type I collagenase (250 UI/rat, Sigma-Aldrich) or saline (sham group) was injected into the left Achilles bone-tendon junction to induce tendon injury. After 4 week, the time required for tendon degeneration to occur $[44,47,48]$, each left Achilles tendon was injected with $20 \mu \mathrm{l}$ allogenic PRP (PRP treatment group), $20 \mu \mathrm{l}$ allogenic TDSC suspension (TDSC treatment group; approximately $10^{4}$ cells $/ \mu \mathrm{l}$ ), $20 \mu \mathrm{l}$ allogenic PRP and $20 \mu \mathrm{l}$ allogenic TDSCs (PRP with TDSC treatment group) or $20 \mu \mathrm{l}$ PBS (control group and sham group) using the same injection technique as for the first injection. Twelve rats from each group were sacrificed at 4 and 8 weeks after the second injection, as in previous studies [8, 47]. Achilles tendon tissue was harvested from both hind limbs. For each group at both time points, three tissue samples were stored at $-80^{\circ} \mathrm{C}$ for realtime reverse transcription (RT) -PCR analysis and western blotting. Six samples were used for mechanical testing and three were fixed, paraffin-embedded and sectioned into $5-\mu \mathrm{m}$ sections for histological staining.

\section{PRP-clot releasate treatment}

The TDSCs at passage two were seeded in a six-well plate at a density of $8 \times 10^{4}$ cells/well and cultured in growth medium with or without with 10\% PRP-clot releasate (PRCR) for 3 days. For blockage of FAK or ERK1/2 autophosphorylation, the PRCR treated TDSCs were incubated with PF573228 (10 $\mu$ m, FAK inhibitor, Tocris, Ellisville, MO, USA) or PD98059 (50 $\mathrm{m}$, ERK1/2 inhibitor, Sigma). During the preparation of PRP-Clot Releasate, the PRP was treated with $22 \mathrm{mM} \mathrm{CaCl}_{2}$ at $3{ }^{\circ} \mathrm{C}$ for $1 \mathrm{~h}$, followed by centrifugation at $2000 \mathrm{~g}$ for $10 \mathrm{~min}$ to activate the platelets. The resulting PRCR was collected by aspiration and stored at $4^{\circ} \mathrm{C}$ until use.

\section{Histology}

Hematoxylin-eosin stained 5- $\mu \mathrm{m}$ sections were analyzed using Aperio's 120-slide ScanScope XT system (Aperio Technologies) under a 40× objective. Six parameters (fiber structure, fiber arrangement, rounding of the nuclei, inflammation, increased vascularity and cell density) were quantified using a 0-3 grading scale: 0 (normal), 1 (slightly abnormal), 2 (moderately abnormal) and 3 (maximally abnormal) (Fig. 1B, Table 1) $[8,47,49]$. In this grading system a perfectly normal tendon would score 0 and a maximally abnormal tendon would score 18 . Three sections were randomly selected from each sample and were evaluated blindly by three independent assessors. The averaged score was used for comparison.

\section{Biomechanical testing}

The biomechanical properties: maximum load to failure and stiffness of the tendons, were determined according to methods previously described [47, 50-53]. Both ends of the sample were fixed on a customdesigned testing jig with a screw clamp, and the whole construct was mounted onto a mechanical testing system (model 5566; Instron, Norwood, MA, USA). The test to failure was performed at a testing speed of $1 \mathrm{~mm} / \mathrm{s}$ and preload of $2 \mathrm{~N}$. The load-displacement curve was plotted. The applied load (in newtons) at the moment of failure was recorded. Stiffness was calculated using the following formula: Stiffness = Maximum load $(\mathrm{N}) /$ Ultimate elongation. The tendon specimens from each group $(\mathrm{n}=6)$ were kept moist with $0.9 \%$ saline irrigation during testing.

\section{Immunohistochemical staining}

Serial sections were stained for type I collagen by immunohistochemistry. The procedure was performed as previously described $[8,47]$. Briefly, paraffin-embedded sections were dried at $60^{\circ} \mathrm{C}$ for 20 min, deparaffinized in xylene and dehydrated through a graded alcohol series. After inactivation of the endogenous peroxidase activity by $3 \%$ hydrogen peroxide, the sections were incubated with $10 \%$ goat 
Table 1. Grading system for histological evaluation

\begin{tabular}{|c|c|c|c|c|}
\hline & \multicolumn{4}{|c|}{ Tendon repair assessment score } \\
\hline & 0 & 1 & 2 & 3 \\
\hline Fiber structure & $\begin{array}{l}\text { Continuous, long } \\
\text { fiber }\end{array}$ & $\begin{array}{c}\text { Slightly } \\
\text { fragmented fiber }\end{array}$ & $\begin{array}{l}\text { Moderately fragmented } \\
\text { fiber }\end{array}$ & $\begin{array}{c}\text { Severely } \\
\text { fragmented fiber }\end{array}$ \\
\hline Fiber arrangement & $\begin{array}{l}\text { Compacted and } \\
\text { parallel }\end{array}$ & $\begin{array}{l}\text { Slightly loose and } \\
\text { wavy }\end{array}$ & $\begin{array}{l}\text { Moderately loose, wavy and } \\
\text { crossing each other }\end{array}$ & $\begin{array}{l}\text { No identifiable } \\
\text { pattern }\end{array}$ \\
\hline Rounding of the nuclei & $\begin{array}{l}\text { Long spindle- } \\
\text { shape cells }\end{array}$ & Slightly rounded & Moderately rounded & Severely rounded \\
\hline $\begin{array}{c}\text { Inflammation } \\
\text { (area infiltrated by } \\
\text { inflamed cells) }\end{array}$ & $<10 \%$ & $10 \%-20 \%$ & $20 \%-30 \%$ & $>30 \%$ \\
\hline $\begin{array}{l}\text { Increased vascularity } \\
\text { (neovascular area) }\end{array}$ & $<10 \%$ & $10 \%-20 \%$ & $20 \%-30 \%$ & $>30 \%$ \\
\hline Cell density & Normal & $\begin{array}{c}\text { Slightly } \\
\text { increased }\end{array}$ & Moderately increased & $\begin{array}{l}\text { Severely } \\
\text { increased }\end{array}$ \\
\hline
\end{tabular}

Table 2. Primers used in real-time RT-PCR analysis

\begin{tabular}{lll}
\hline Primer & Sequence(5' to 3') $^{\prime}$ & Size(bp) \\
\hline Col I - F & TGGCCAAGAAGACATCCCTGAAGT & 81 \\
Col I - R & ACATCAGGTTTCCACGTCTCACCA & \\
$\begin{array}{l}\text { Scleraxis-F } \\
\text { Scleraxis-R }\end{array}$ & ACTCATCCCGACCGAGCCAGC & 116 \\
Tenascin C-F & GACCGCAGGCTTCACCCACCAG & \\
Tenascin C-R & AGCACGGGTGTTTTATAGC & 176 \\
SOX9- F & TAAATTCCCAGTGTGCATCCGCGA & 117 \\
SOX9- R & TTGACGTGTGGCTTGTTCTTGCTG & \\
Runx2- F & TGATGACACTGCCACCTCTGACTT & 163 \\
Runx2- R & TGGATAGTGCATTCGTGGGTTGGA & \\
PPAR $\gamma-$ F & CGAGCCCTGGCAAAGCATTTGTAT & 90 \\
PPAR $\gamma-$ R & TGTCTTTCCTGTCAAGATCGCCCT & \\
$\beta$-actin- F & TTGCTGACAGGATGCAGAAGGAGA & 159 \\
$\beta$-actin- R & ACTCCTGCTTGCTGATCCACATCT & \\
\hline
\end{tabular}

serum at $37^{\circ} \mathrm{C}$ for $30 \mathrm{~min}$ and with primary antibody against type I collagen (Abcam) at $4^{\circ} \mathrm{C}$ overnight. Next, the sections were further incubated with biotinylated goat anti-mouse IgG (Abcam) at $37^{\circ} \mathrm{C}$ for $30 \mathrm{~min}$, followed by incubation with a Streptavidin-Biotin Complex working solution (SABC, Maixin, Fujian, China) at $37^{\circ} \mathrm{C}$ for $30 \mathrm{~min}$, developed in 3,3-diaminobenzidine (DAB, Sigma-Aldrich), and then counterstained with hematoxylin. The sections were examined under light microscopy. Five 200x microscopic fields of each section were observed randomly. DAB intensity was determined by Image-pro plus software (Media Cybernetics, Inc., Rockville, MD, USA).

\section{Western blots}

Total protein was extracted from TDSCs $\left(5 \times 10^{6}\right.$ cells) in RIPA buffer (Beyotime Biotechnology, Shanghai, China) and from tendon tissues digested in a homogeneous buffer of $8 \mathrm{M}$ urea, $50 \mathrm{mM}$ Tris- $\mathrm{HCl}$ at pH 8.0, 1 mM dithiothreitol, and 1 m MEDTA. Protein concentration was determined using a Pierce BCA Protein Assay Kit (Thermo Scientific, Waltham, MA, USA). Proteins extracted from tendon tissue (25 $\mu \mathrm{g})$ or TDSCs $(50 \mu \mathrm{g})$ were separated on $15 \%$ and $8 \%$ sodium dodecyl sulfate-polyacrylamide gel electrophoresis, respectively. Tendon tissue proteins were transferred onto polyvinylidene fluoride (PVDF) membranes (Pall Corporation, Port Washington, NY, USA) and TDSC samples were electrophoretically transferred onto nitrocellulose membranes (Amersham Bioscience, Piscataway, NJ, USA) at $80 \mathrm{~V}$ for $150 \mathrm{~min}$. Membranes were blocked by incubation with $5 \%$ nonfat milk power in $0.1 \mathrm{M}$ Tris buffered saline containing $0.1 \%$ Tween-20 (TBST; pH 7.4) at $4^{\circ} \mathrm{C}$ for $4 \mathrm{~h}$ (tendon tissue) or room temperature for $30 \mathrm{~min}$ (TDSC). The membranes were then incubated at $4^{\circ} \mathrm{C}$ overnight with type I collagen, SCXA, Tenascin-c, p-p38, p38, p-FAK, FAK, p-ERK1/2 and ERK1/2 antibodies (1:1000 dilution, all antibodies from Abcam). $\beta$-actin was used as an internal control. Membranes were washed three times with TBST and incubated with horseradish peroxidase-conjugated secondary antibody (anti-rabbit or anti-mouse immunoglobulin (Ig)G-peroxidase conjugate, 1 : 2000 dilution; Jackson ImmunoResearch, West Grove, PA, USA) at room temperature for 45- 
Fig. 1. Characterization of TDSCs and semiquantitative histology scoring system. (A) Flow cytometry analysis of the expression of cell surface markers related to mesenchymal stem cell markers (CD44 and CD90), hematopoietic stem cell marker (CD34) and the leukocyte marker CD45 on TDSCs. (B) Example micrographs $(40 \times)$ of hematoxylin-stained Achilles tendon sections graded with histology scores 0 (normal), 1 (slightly abnormal), 2 (moderately abnormal) or 3 (maximally abnormal) for the six parameters (fiber structure, fiber arrangement, nuclear rounding, inflammation, angiogenesis and cell density).
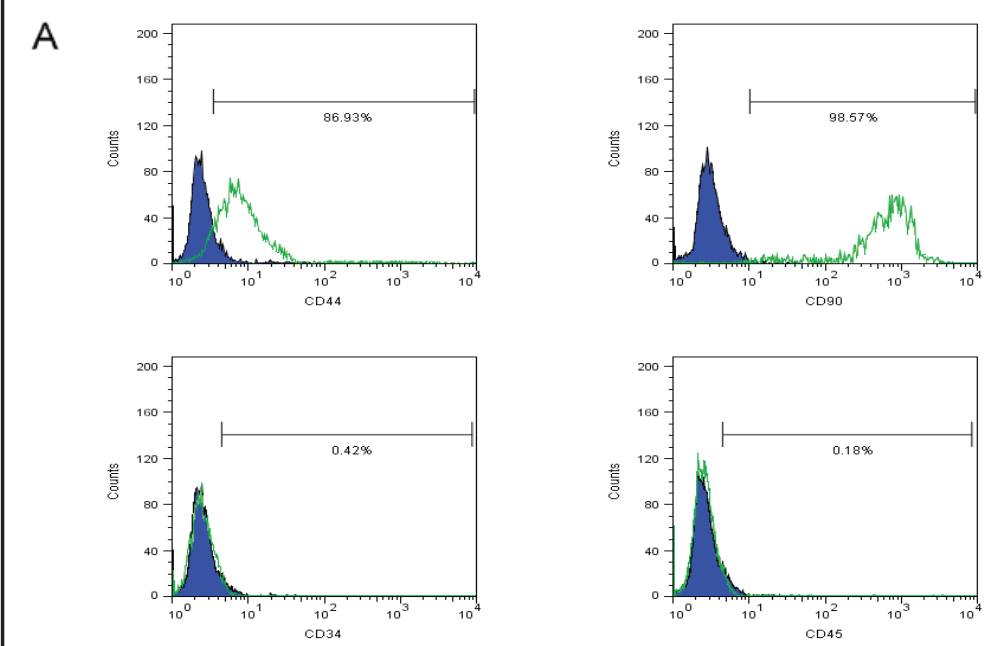

B

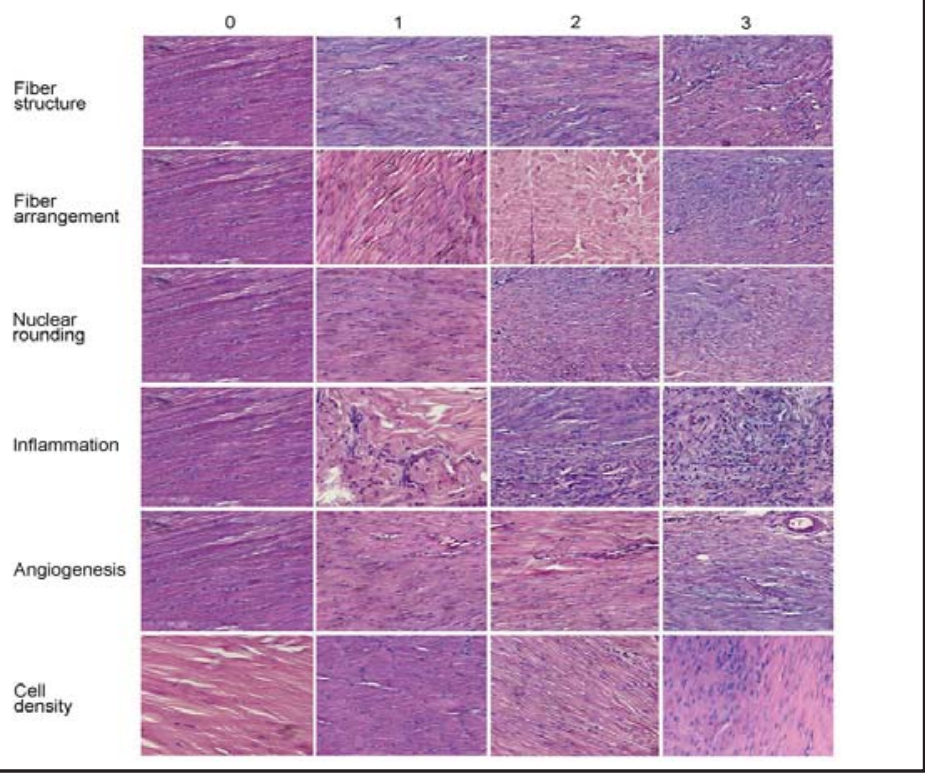

$60 \mathrm{~min}$. Proteins were visualized using an enhanced chemiluminescence system (KeyGen Biotechnology, Nanjing, Jiangsu). Protein levels were normalized to $\beta$-actin using Image J analysis software (NIH).

\section{Real-Time RT-PCR analyses of gene expression}

Total RNA was isolated from tissue using Trizol (Invitrogen, Carlsbad, CA, USA). First-strand cDNA was synthesized using the RevertAid First Strand cDNA Synthesis Kit (MBIFermentas, Maryland, USA). The mRNA levels of type I collagen, SCX, Tenascin-c, SOX9, Runx2 and PPAR $\gamma$ were determined by the ABI PRISM 7300 System (Applied Biosystems, Foster City, CA, USA) using the Quant qRT-PCR (SYBR Green I) Kit (TIANGEN, Beijing, China) according to the manufacturer's instructions. The PCR reaction was as follows: $10 \mathrm{~min}$ at $95^{\circ} \mathrm{C}$ (initial denaturation); $95^{\circ} \mathrm{C}$ for $30 \mathrm{~s}, 45 \mathrm{~s}$ at $55-62^{\circ} \mathrm{C}, 30 \mathrm{~s}$ at $72^{\circ} \mathrm{C}$, repeated 45 times (amplification). $\beta$-actin was used as the endogenous control. Negative controls (blanks, no RNA) were included to identify contamination. The final results were determined from three independent assays. The relative quantification of target RNA was achieved by the comparative threshold cycle (CT) method and the target CT number was normalized to $\beta$-actin. Primers for qRT-PCR are listed in Table 2.

\section{Statistical analysis}

All data were reported as the mean \pm standard deviation. Analysis of variance (ANOVA) was used for data with multiple comparisons and a non-parametric test was used for non-parametric (ranked) data. A p-value $<0.05$ was considered to be statistically significant. 
Fig. 2. Histology scores of tendon healing. Analysis of Achilles tendon section histology $4(n=6)$ and 8 weeks $(n=6)$ after the injection of treatment cocktails of PRP, TDSCs, PRP with TDSCs and control into rat Achilles tendon injured by collagenase injection. (A) Sum of all six histology parameters. Scores for (B) fiber arrangement, (C) fiber structure, (D) angiogenesis, (E) nuclear rounding,

(F) inflammation, (G) cell density are shown. * and \# indicated the significant difference, * with respect to the control group; \# with respect to the PRP treatment group.

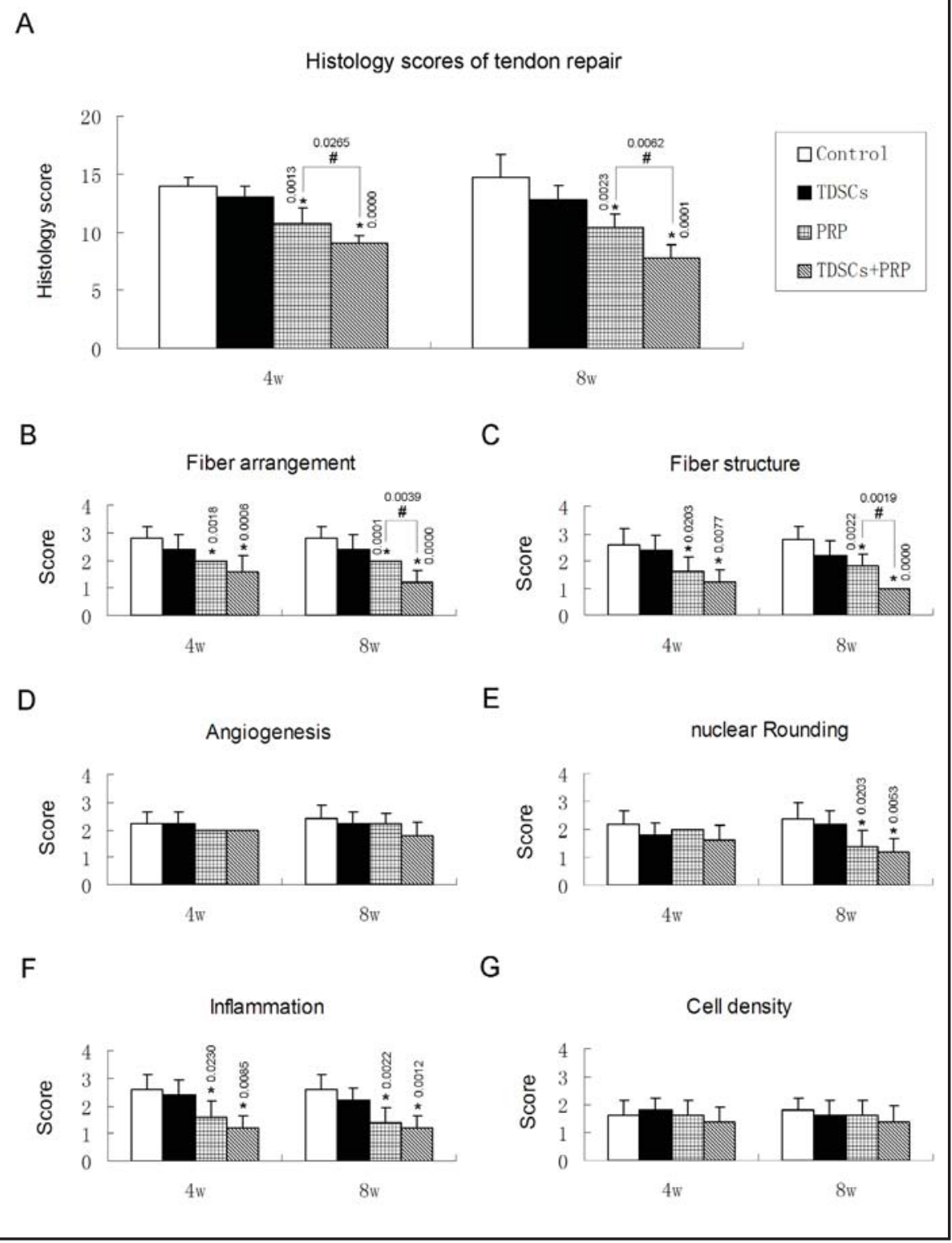

\section{Results}

\section{PRP combined with TDSCs improves the histology of repaired tendon}

To evaluate the effect of single or combined treatments of TDSCs and PRP on collagenase induced Achilles tendon injury in rat, we semi-quantitatively analyzed six histological parameters of tendon quality. H\&E stained sections of collagenase injected rat Achilles tendon harvested 4 and 8 weeks after treatment injections (PRP, TDSCs or PRP with TDSC) were given histology scores for fiber arrangement, fiber structure, inflammation, nuclear rounding, angiogenesis and cell density. The average histology scores for fiber arrangement, fiber structure and inflammation were significantly lower for the PRP and PRP with TDSC groups than the control group at both 4 and 8 weeks after treatment injections (Fig. 2A, B, $\mathrm{C}$ and $\mathrm{F}$ ). The average histology scores for nuclear rounding were significantly lower for the PRP and PRP with TDSC groups than the control group at 8 weeks after treatment injections (Fig. 2E). Scores for angiogenesis and cell density were similar in all groups at both time points (Fig. 2D and G). Treatment with TDSCs had no significant effect on histology scores 
Fig. 3. The biomechanical properties of Achilles tendon tissue. The maximum load to failure (A) and the mean stiffness (B) of Achilles tendon tissue $4(n=6)$ and 8 weeks $(n=6)$ after the injection of treatment cocktails of PRP, TDSCs, PRP with TDSCs, control and sham into rat Achilles tendon injured by collagenase injection. *, \$ and \# indicate the significant differences, at least $\mathrm{p}<0.05$; * with respect to the control group; \$ with respect to the sham group; \# with respect to the PRP treatment group.

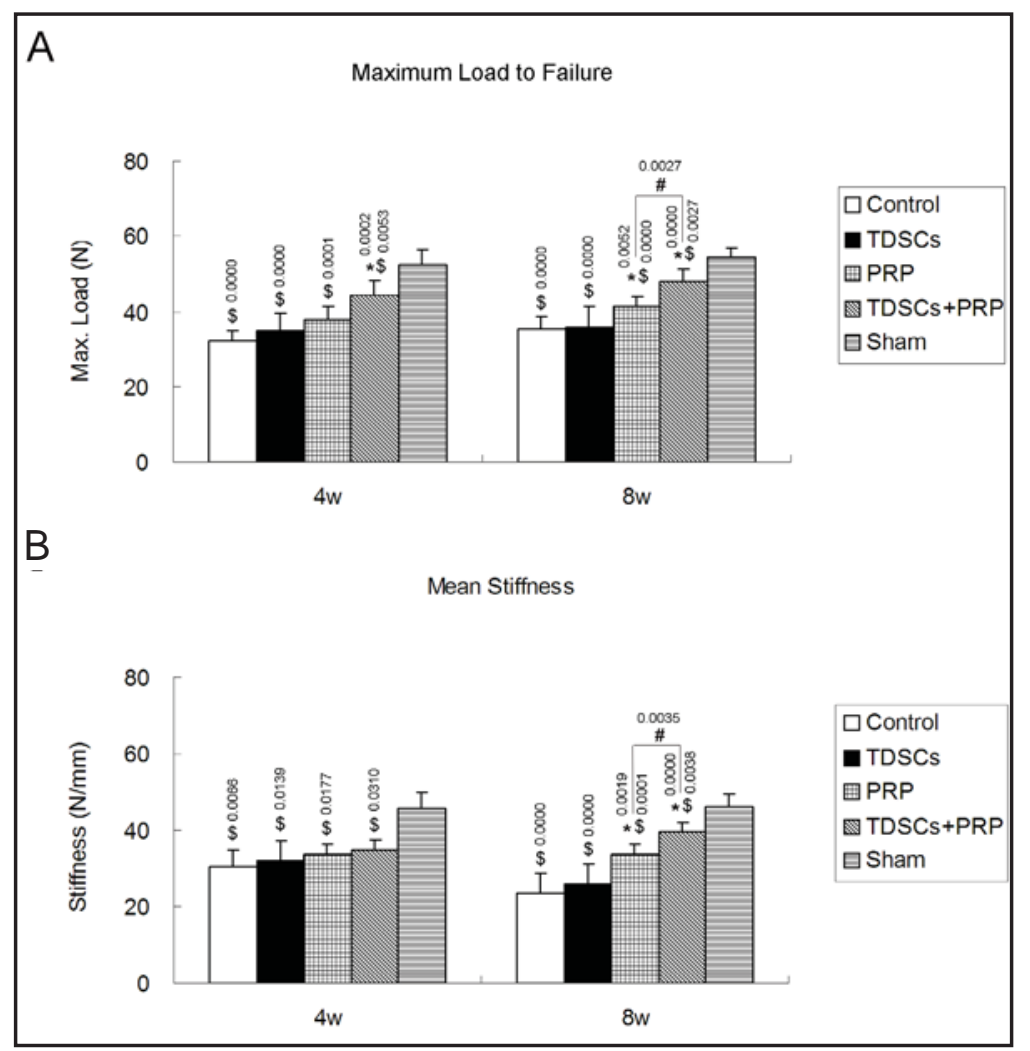

in the present study. These results confirm that PRP treatment improves tendon healing in collagenase-induced Achilles tendinopathy in rat [54] and reveal that TDSCs enhance its positive effects.

PRP and TDSCs improved the maximum strength and stiffness of repaired tendon

The biomechanical properties (maximum load to failure and mean stiffness) of healing tendons were measured in each experimental group (Fig. 3). The ultimate failure load was significantly lower than normal tendon (sham group) for all treated groups (including the control), at both 4 and 8 weeks after injection. Although still significantly lower than normal tendon, the maximum load of PRP with TDSC tendons was significantly higher than the control group at weeks 4 and 8. In addition, the maximum load of the PRP group only became significantly different from the control group by week 8. The maximum load of the TDSC group was similar to the control group at both time points (Fig. 3A). These results show that while PRP treatment improves tensile strength, it is significantly improved by the addition of TDSCs to PRP.

Next, we measured tendon stiffness as an indicator of tendon healing. Four weeks after treatment injections, the mean stiffness of all experimental groups was similar to that of the control group $(30.4 \pm 4.1 \mathrm{~N} / \mathrm{mm})$, but significantly lower than that of the sham tendon (45.4 $\pm 4.8 \mathrm{~N} / \mathrm{mm}$ ) (Fig. 3B). By week 8, the PRP and PRP with TDSC groups were still significantly lower than that of the sham tendon $(46.1 \pm 3.6 \mathrm{~N} / \mathrm{mm})$, but nevertheless significantly higher than the control group. Furthermore, the mean stiffness of the PRP with TDSC group $(39.4 \pm 2.5 \mathrm{~N} / \mathrm{mm})$ was significantly higher than that of the PRP group $(33.5 \pm 2.9 \mathrm{~N} / \mathrm{mm})$ (Fig. 3B). These results show that the addition of TDSCs enhances the PRP treatment's improvement of tendon stiffness.

PRP with TDSCs increases tenocyte marker expression and decreases non-tenocyte marker expression during Achilles tendon healing

To gain insight into the cell type composition of healing tendon in our experimental groups, we investigated the gene and protein expression of a panel of tenocyte-related and 


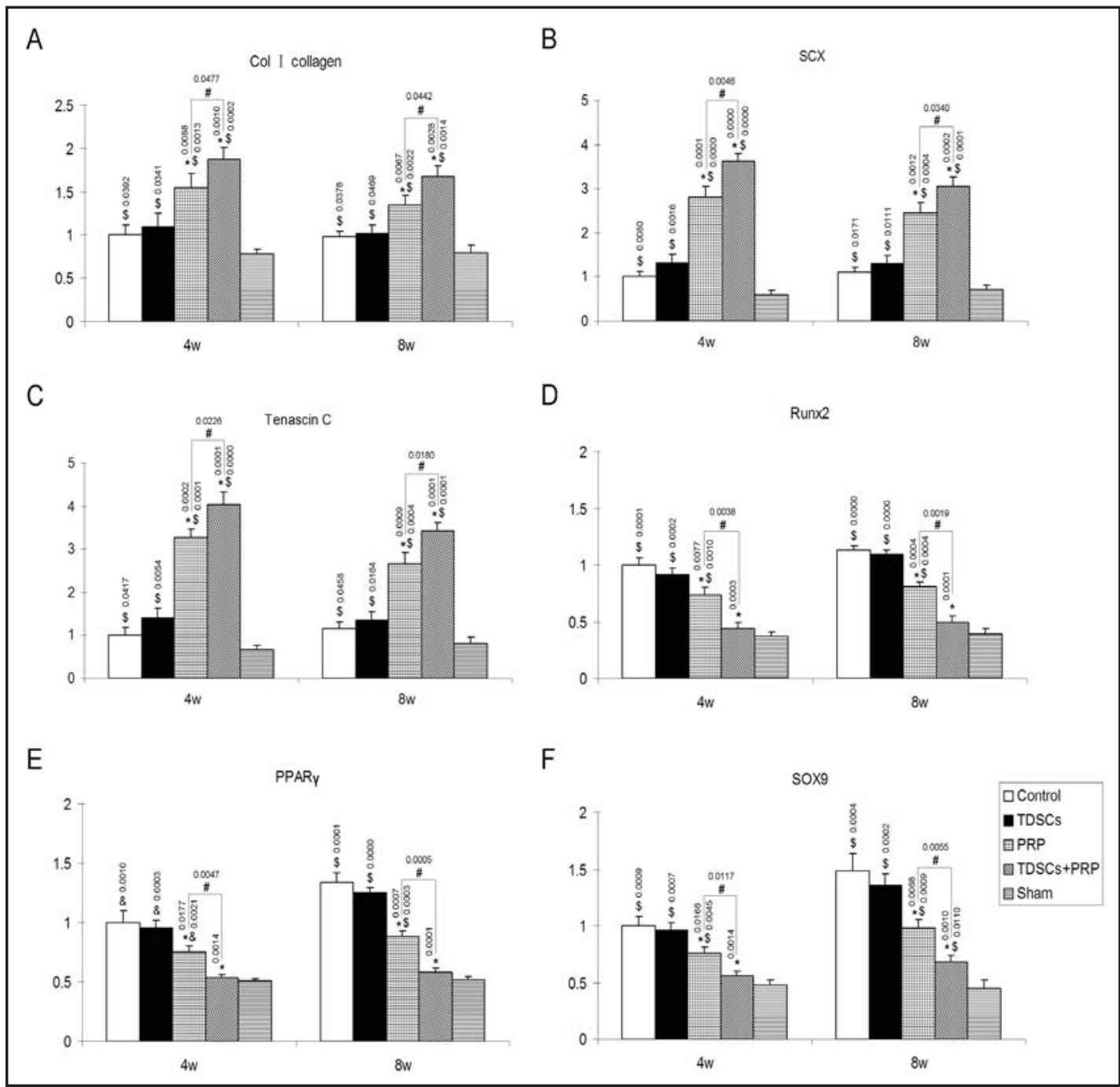

Fig. 4. The mRNA expression of tenocyte and non-tenocyte markers during Achilles tendon healing. Realtime RT-PCR analysis of the relative mRNA expression of type I collagen (A), SCX (B), Tenascin C (C), Runx2 (D), PPAR $\gamma$ (E) and SOX9 (F) mRNA normalized to $\beta$-actin mRNA in Achilles tendon tissue 4 and 8 weeks after the injection of treatment cocktails of PRP, TDSCs, PRP with TDSCs, control and sham into rat Achilles tendon injured by collagenase injection. *, \$ and \# indicate the significant differences; * with respect to the control group; \$ with respect to the sham group; \# with respect to the PRP treatment group.

non-tenocyte markers at 4 and 8 weeks after the treatment injections. Using qRT-PCR to analyze gene expression, we observed an increase in tenocyte-related (Col I, SCX and Tenascin C) and a decrease in the expression of non-tenocytegenes (Runx2, PPAR $\gamma$ and SOX9) in all experimental groups compared to normal tendon (sham) (Fig. 4). Compared to the other groups, the PRP with TDSC group elicited a much greater increase in tenocyte-related gene expression and a greater reduction of non-tenocyte gene expression.

We next measured the protein levels of tenocyte-related markers collagen type I, SCX and Tenasc in $\mathrm{C}$ by western blotting (Fig. $5 \mathrm{~A}$ ). Using densitometry to measure reactive band intensity we found that at both time points, PRP with TDSC treatment yielded the highest type I collagen, SCX, and Tenascin C protein expression levels. These were significantly higher than the PRP group, which in turn were significantly higher than those of the control and sham group (Fig. 5 B, C and D). These in vivo results were consistent with our in vitro findings showing that PRP treatment promotes tenocyte differentiation. 


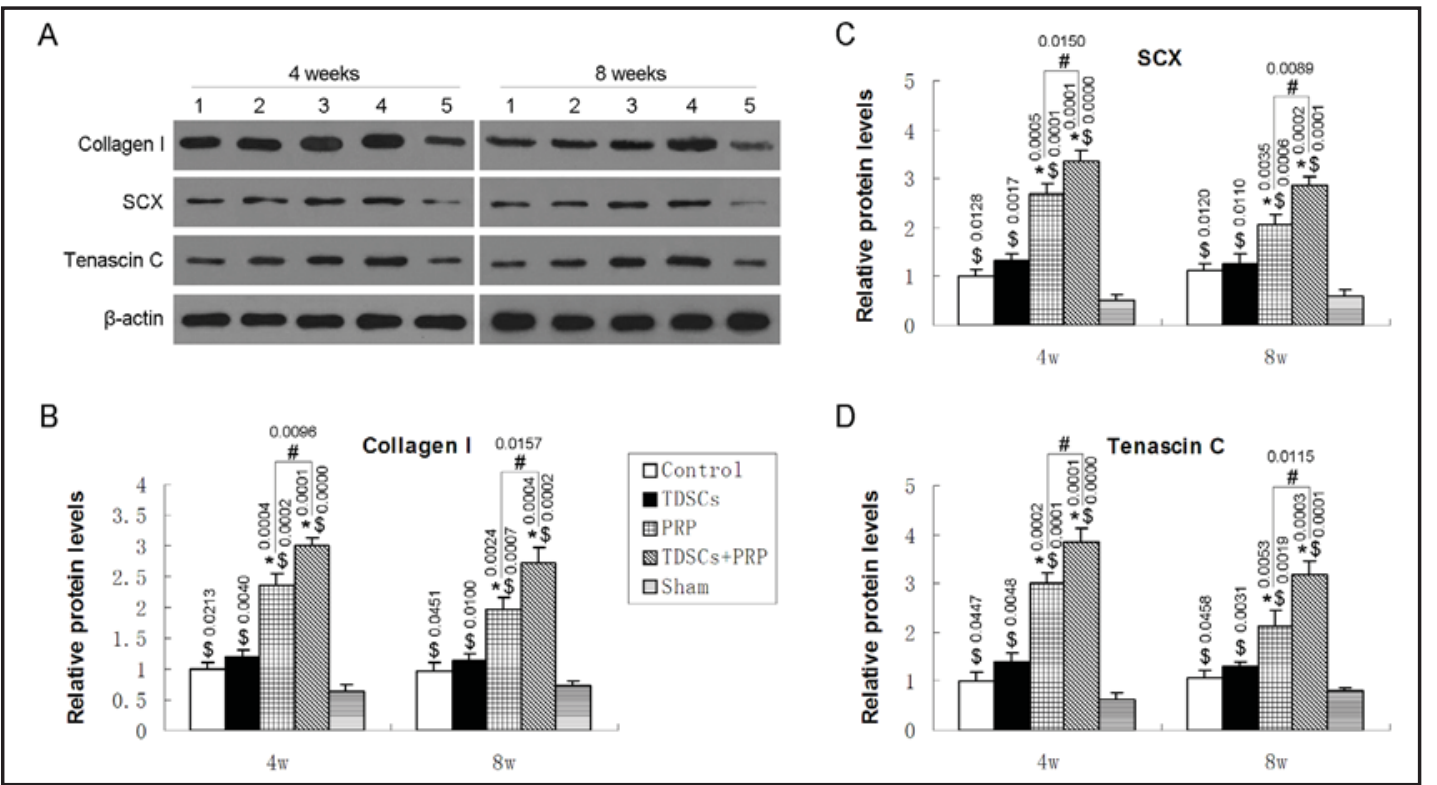

Fig. 5. The protein levels of tenocyte markers during Achilles tendon healing. Protein levels of Collagen I, SCX, Tenascin C depicted by western blotting (A) of protein extracts from Achilles tendon tissue 4 and 8 weeks after the injection of treatment cocktails of PRP, TDSCs, PRP with TDSCs or PBS (control) into collagenase or saline (sham) injected rat Achilles tendon. Beta-actin was used as a control for total protein quantity. 1, Control; 2, TDSCs; 3, PRP; 4, PRP with TDSCs; 5, Sham group. Densitometry of Collagen I (B), SCX (C) and Tenascin C (D) immunoreactive bands provides an estimate of protein quantities. *, \$ and \# indicate the significant differences; * with respect to the control group; \$ with respect to the sham group; \# with respect to the PRP treatment group.

Fig. 6. Increased Collagen Type I production in PRP and TDSC treated tendons. Micrographs (A, $200 \times$ ) of type I collagen expression depicted by immunohistochemical staining of Achilles tendons 4 and 8 weeks after the injection of treatment cocktails of PRP, TDSCs, PRP with TDSCs, control and sham into rat Achilles tendon injured by collagenase injection. (B) 3,3-diaminobenzidine (DAB) intensity of Collagen I immunohistochemical staining in samples depicted in (A). * \$ and \# indicate the significant differences; * with respect to the control group; \$ with respect to the sham group; \# with respect to the PRP treatment group.

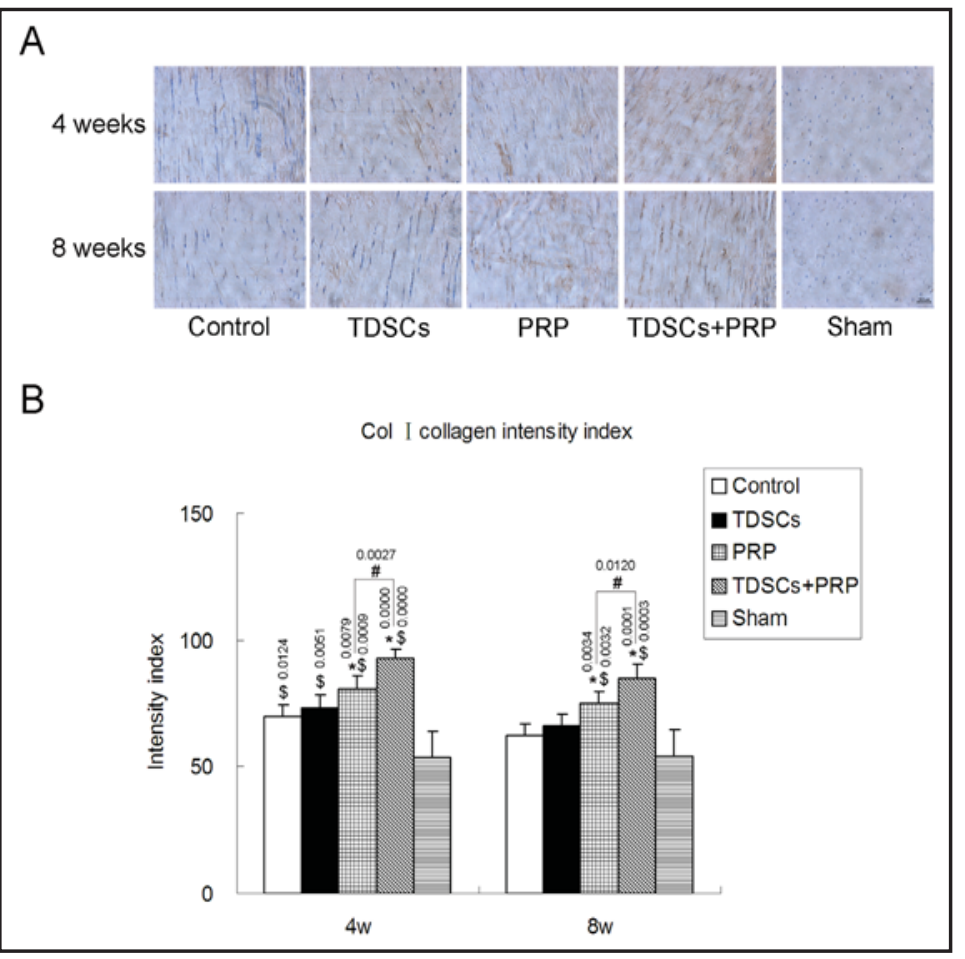

Increased Collagen Type I in PRP and TDSC treated tendons

To determine collagen production during healing in the treatment groups we detected collagen type I expression by immunohistochemistry (Fig. 6A). When we quantified the DAB 
A

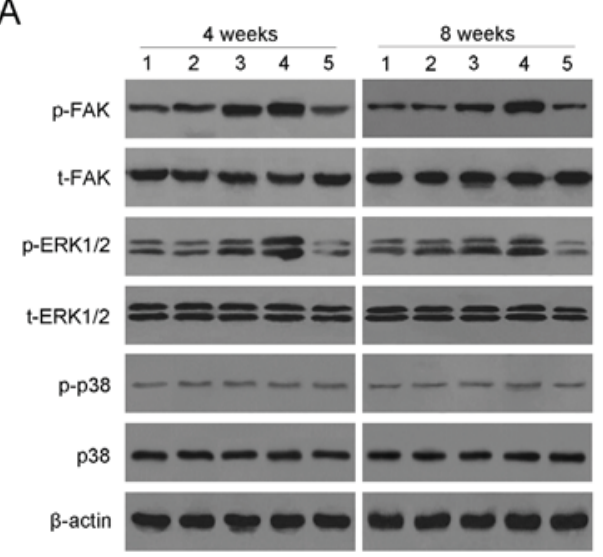

C

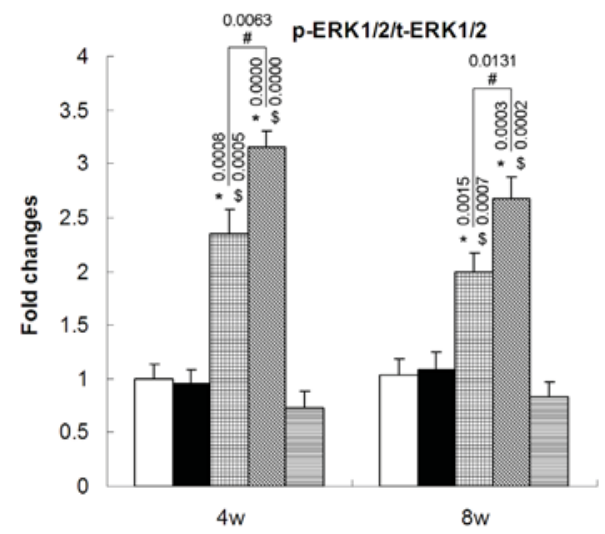

B

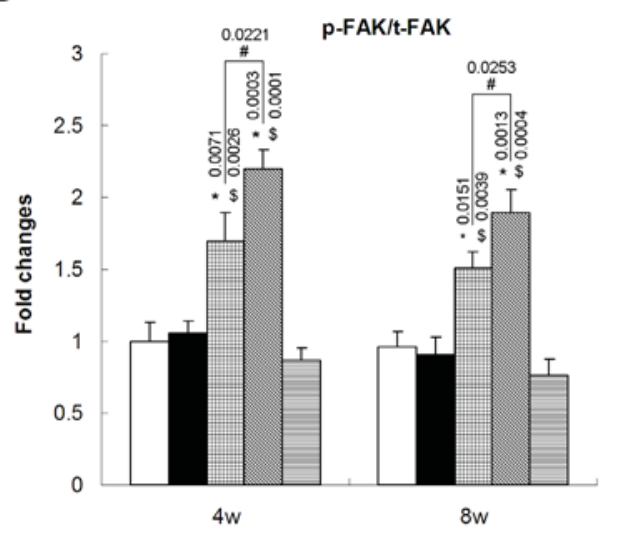

D

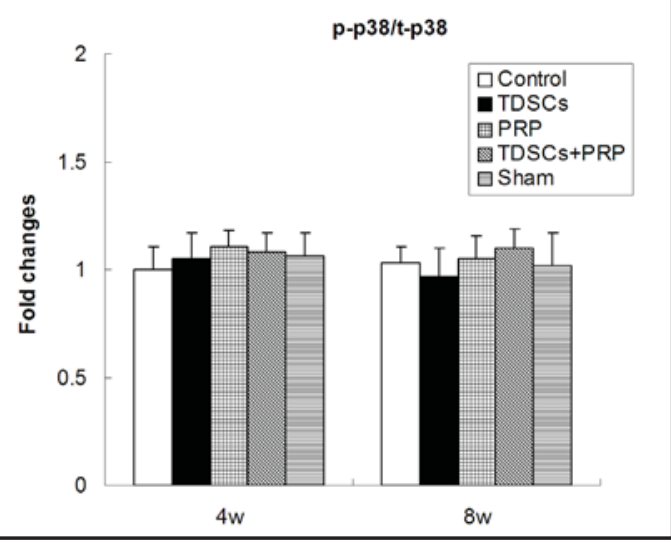

Fig. 7. The activation of FAK/ERK1/2 signaling pathway during Achilles tendon healing. FAK/ERK1/2 signaling pathway activity in Achilles tendons 4 and 8 weeks after the injection of treatment cocktails of PRP, TDSCs, PRP with TDSCs or PBS (control) into collagenase or saline injected (sham) rat Achilles tendon analyzed by western blotting (A) of phospho-FAK (p-FAK), total FAK (t-FAK), phospho-ERK1/2 (p-ERK1/2), total ERK1/2 (t-ERK1/2), phospho-p38 (p-p38) and total p38 (t-p38). 1, Control; 2, TDSCs; 3, PRP; 4, PRP with TDSCs; 5, Sham group. (B) Quantification of p-FAK immunoreactive band intensity normalized to t-FAK. (C) Quantification p-ERK1/2 immunoreactive band intensity normalized to t-ERK1/2. (B) Quantification of p-p38 immunoreactive band intensity normalized to t-p38. *, \$ and \# indicate the significant differences; * with respect to the control group; $\$$ with respect to the sham group; \# with respect to then PRP treatment group.

intensity, we found the type I collagen intensity index of the PRP with TDSC treatment to be significantly higher than those of the other groups at both time points (Fig. 6B).

The FAK and ERK1/2 signaling pathways are activated in Achilles tendon healing

We next investigated whether the positive effects of PRP and PRP with TDSC on healing tendons were mediated by a differential activation of FAK and ERK1/2 signaling pathway components. We measured by western blotting p-FAK and p-ERK1/2 and p-p38 protein levels in tendon tissue from all experimental groups (Fig. 7) and found higher levels of p-FAK/tFAK and p-ERK1/2/t-ERK1/2 in the PRP and PRP with TDSC groups, but no change at p38 phosphorylation levels in all groups. These results suggest that the observed healing effects of PRP and PRP with TDSC could be mediated by these two signaling pathways. Since FAK signaling is involved in tenogenic differentiation of MSCs in vitro [41,42], we next investigated FAK signaling in PRP mediated TDSC differentiation in vitro. When we treated TDSC cultures with $10 \%$ PRP, the phosphorylation levels of FAK and ERK1/2 increased significantly, as 


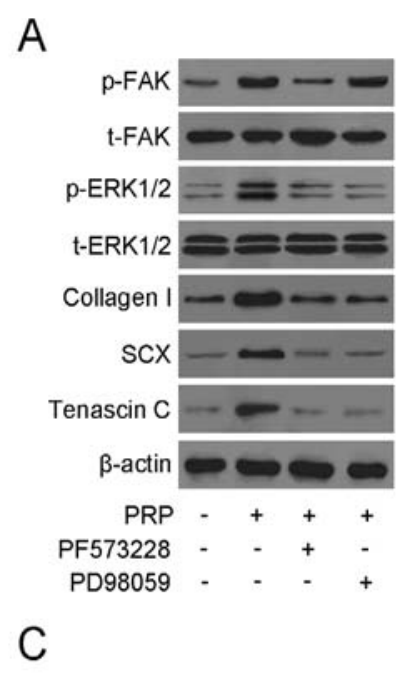

B
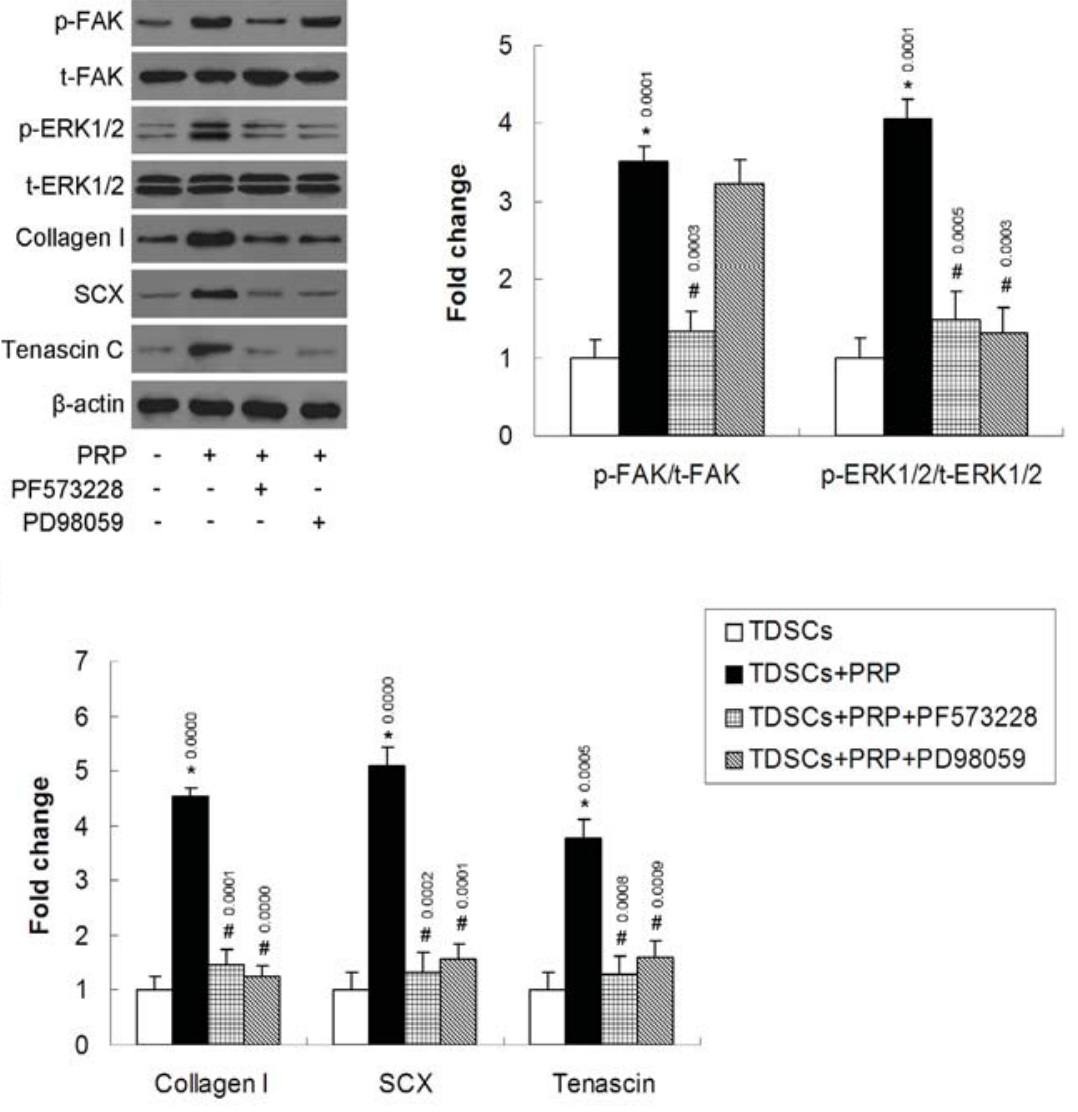

Fig. 8. The FAK/ERK1/2 signaling pathways are involved in PRP mediated TDSC differentiation in vitro. Expression of tenocyte-related genes (Collagen I, SCX and Tenascin C) and FAK/ERK1/2 signaling pathway components in TDSCs cultured in growth medium alone or medium supplemented with 10\% PRP, 10\% PRP+ PF573228 (10 $\mu \mathrm{m}$, FAK inhibitor) or 10\% PRP+ PD98059 (50 $\mu \mathrm{m}$, ERK1/2 inhibitor) for 3 days. (A) Protein expression depicted by western blotting. (B) Quantification of p-FAK and p-ERK1/2 immunoreactive band intensities (A) normalized to t-FAK and t-ERK1/2, respectively. (C) Real-time RT-PCR analysis of Collagen I, SCX, Tenascin mRNA. * and \# indicate the significant differences, * with respect to the TDSC group; \# with respect to the PRP with TDSCs group.

demonstrated by western blotting and densitometry (Fig. 8). Likewise, tenocyte-related protein levels increased (Col I, SCX and Tenascin C, Fig. 8A and 8C), indicating differentiation along a tenogenic pathway. When we inhibited FAK (using FAK inhibitor; PF573228, 10 $\mu \mathrm{m}$ )

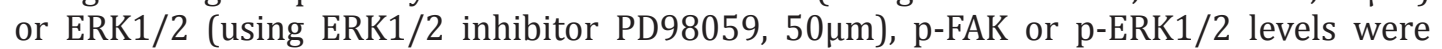
reduced (Fig. 8A and 8B) and protein expression levels of tenocyte markers Col I, SCX and Tenascin $\mathrm{C}$ also decreased (Fig. 8A and $8 \mathrm{C}$ ). These results raise the possibility that the FAK and ERK1/2 signaling pathways are involved in TDSC differentiation toward the tenocyte lineage after PRP treatment during Achilles tendon healing.

\section{Discussion}

Our results show that combining TDSCs with PRP significantly enhances tendon healing compared with PRP alone in a model of Achillestendinopathy. Improved healing was associated with higher mRNA and protein expression of tenocyte-related markers and lower expression of non-tenocyte markers. Furthermore, we observed a strong activation 


\section{Cellular Physiology and Biochemistry}

Cell Physiol Biochem 2014;34:2153-2168

\begin{tabular}{l|l}
\hline DOI: $10.1159 / 000369659$ & (C) 2014 S. Karger AG, Basel
\end{tabular}

www.karger.com/cpb

Chen et al.: TDSCs Promote PRP Induced Healing in Achilles Tendinopathy

of FAK and ERK1/2 signaling in PRP treated tissues, implying an involvement of these pathways in tenocyte differentiation. We also found that inhibition of FAK and ERK signaling in PRP-induced TDSC differentiation abolished tenocyte-related marker expression. Our data suggests that tendon healing by PRP could be due to PRP's stimulation of tenocyte differentiation by the activation of FAK and ERK signaling.

It has previously been shown that PRP treatment improves tendon healing in collagenaseinduced Achilles tendinopathy in rat [54]. The mechanism by which PRP improves tendon healing is generally considered to be the effect of its growth factors, many of which are known to be involved in tendon healing [55-57]. Our study showed that the concentrations of TGF- $\beta 1$ and PDGF-BB were greater in PRP compared to whole blood. TheTGF- $\beta 1$ concentration was 5.9 -fold greater in PRP $(3018.4 \pm 103.2 \mathrm{ng} / \mathrm{ml})$ compared to whole blood $(511.6 \pm 45.4 \mathrm{ng} / \mathrm{ml})$. The PDGF-BB concentration was 3.8 -fold greater in PRP $(9.5 \pm 1.6 \mathrm{ng} / \mathrm{ml})$ compared to whole blood $(2.5 \pm 0.3 \mathrm{ng} / \mathrm{ml})$. Studies in vitro and in vivo have shown that PRCR enhances tendon healing by increasing tenocyte number and production of collagen [27, 28, 58]. In agreement with these results, our experiments showed that PRP-treated tendons had increased type I collagen and tenocyte-related gene and protein expression, indicative of an increase in tenocyte number and collagen production.

FAK signaling is required for MSC differentiation towards a tenocyte fate [41, 42]. We found not only that PRP treated tendon displays increased FAK and ERK1/2 signaling, but that PRP induced TDSC differentiation along a tenocyte fate requires FAK and ERK1/2 signaling. These observations place FAK and ERK1/2 central to tenocyte lineage determination and provide a starting point for dissecting tenogenic signaling pathways in combination with the BMP and Smad8 signaling pathways known to impact tenocyte differentiation $[17,43]$.

Our study showed that while PRP had a positive effect on tendon healing, this was significantly enhanced by TDSCs. The mechanism by which TDSCs enhance the effect of PRP could be two-fold. PRP could stimulate the donor TDSCs by promoting their differentiation into active tenocytes $[21,29]$ and by inhibiting differentiation into non-tenocyte lineages [21]. In addition, the transplanted TDSCs might produce tropic paracrine factors that promote healing. In fact, Ni et al. suggested that this was the mechanism responsible for tendon healing by TDSCs in their patellar tendon window defect model because, after a few days, they could not detect the transplanted GFP-labelled cells despite noting a marked improvement in healing [22].

TDSC injection alone did not improve healing. This is in contrast to Ni et al. [22] who showed that TDSCs promote tendon repair. However, besides testing TDSCs in a different model (patellar tendon window defect model), $\mathrm{Ni}$ and co-workers transplanted TDSCs in a fibrin based scaffold. Indeed, since our PRP suspension also contains fibrin, the improved healing by a PRP with TDSC injection potentially reflects a positive effect of fibrin on TDSCs' role in tendon healing. We propose that a manipulation of experimental conditions such as the injection schedule and TDSC differentiation status might lead to improved healing in the collagenase induced Achilles tendinopathy model.

Allogenic PRP and TDSCs were used in our study. With the possibility of translating our findings into clinical practice, it would be advantageous to use autologous PRP to prevent infections. However, its use is only advantageous if combined with autologous TDSCs. The safety of allogenic TDSC transplants as well as the efficiency of autologous TDSC transplants remain to be determined.

In summary our work demonstrates that for the first time the addition of TDSC to a PRP treatment improves healing in collagenase induced Achilles tendinopathy. We also show that PRP upregulates FAK and ERK1/2 dependent tenogenic gene expression in TDSCs, raising the possibility that tenogenic differentiation contributes to the healing process. Future studies to track the TDSCs after injection using labeled cells $[22,47]$ should help clarify their differentiation status and potential contribution to tendon healing. Furthermore, a longer follow up period of at least 12-16 weeks after a PRP with TDSC injection would be useful to determine the treatment's long-term effects. This study provides a starting point for further exploring a PRP with TDSC combination therapy for potential clinical application. 


\section{Cellular Physiology and Biochemistry}

Cell Physiol Biochem 2014;34:2153-2168

\begin{tabular}{l|l}
\hline DOI: $10.1159 / 000369659$ & (C) 2014 S. Karger AG, Basel
\end{tabular}

www.karger.com/cpb

Chen et al.: TDSCs Promote PRP Induced Healing in Achilles Tendinopathy

\section{Acknowledgments}

This study was supported by Natural Science Foundation of China (81301557).

\section{Disclosure Statement}

The authors declare that they have no competing interests.

\section{References}

1 Sharma P, Maffulli N: Biology of tendon injury: Healing, modeling and remodeling. J Musculoskelet Neuronal Interact 2006;6:181-190.

$\longrightarrow 2$ Hoffmann A, Gross G: Tendon and ligament engineering in the adult organism: Mesenchymal stem cells and gene-therapeutic approaches. Int Orthop 2007;31:791-797.

-3 Awad HA, Boivin GP, Dressler MR, Smith FN, Young RG, Butler DL: Repair of patellar tendon injuries using a cell-collagen composite. J Orthop Res 2003;21:420-431.

4 Chong AK, Ang AD, Goh JC, Hui JH, Lim AY, Lee EH, Lim BH: Bone marrow-derived mesenchymal stem cells influence early tendon-healing in a rabbit achilles tendon model. J Bone Joint Surg Am 2007;89:74-81.

-5 Ouyang HW, Goh JC, Thambyah A, Teoh SH, Lee EH: Knitted poly-lactide-co-glycolide scaffold loaded with bone marrow stromal cells in repair and regeneration of rabbit achilles tendon. Tissue Eng 2003;9:431439.

-6 Moshaverinia A, Xu X, Chen C, Ansari S, Zadeh HH, Snead ML, Shi S: Application of stem cells derived from the periodontal ligament or gingival tissue sources for tendon tissue regeneration. Biomaterials 2014;35:2642-2650.

7 Deng D, Liu W, Xu F, Yang Y, Zhou G, Zhang WJ, Cui L, Cao Y: Engineering human neo-tendon tissue in vitro with human dermal fibroblasts under static mechanical strain. Biomaterials 2009;30:6724-6730.

$>8$ Chen JM, Willers C, Xu J, Wang A, Zheng MH: Autologous tenocyte therapy using porcine-derived bioscaffolds for massive rotator cuff defect in rabbits. Tissue Eng 2007;13:1479-1491.

-9 Beerts C, Seifert C, Zimmerman M, Felix E, Suls M, Marien T, Broeckx S, Spaas JH: Desmitis of the accessory ligament of the deep digital flexor tendon: A regenerative approach. J Tissue Sci Engin 2013;4:1-7.

10 Broeckx S, Zimmerman M, Aerts D, Seys B, Suls M, Marien T, Spaas JH: Tenogenesis of equine peripheral blood-derived mesenchymal stem cells: In vitro versus in vivo. J Tissue Sci Engin 2012;3:1-6.

11 Chen X, Song XH, Yin Z, Zou XH, Wang LL, Hu H, Cao T, Zheng M, Ouyang HW: Stepwise differentiation of human embryonic stem cells promotes tendon regeneration by secreting fetal tendon matrix and differentiation factors. Stem Cells 2009;27:1276-1287.

12 Almarza AJ, Augustine SM, Woo SL: Changes in gene expression of matrix constituents with respect to passage of ligament and tendon fibroblasts. Ann Biomed Eng 2008;36:1927-1933.

13 Jelinsky SA, Archambault J, Li L, Seeherman H: Tendon-selective genes identified from rat and human musculoskeletal tissues. J Orthop Res 2010;28:289-297.

14 Schwarz R, Colarusso L, Doty P: Maintenance of differentiation in primary cultures of avian tendon cells. Exp Cell Res 1976;102:63-71.

15 Yao L, Bestwick CS, Bestwick LA, Maffulli N, Aspden RM: Phenotypic drift in human tenocyte culture. Tissue Eng 2006;12:1843-1849.

16 Tasso R, Augello A, Carida M, Postiglione F, Tibiletti MG, Bernasconi B, Astigiano S, Fais F, Truini M, Cancedda R, Pennesi G: Development of sarcomas in mice implanted with mesenchymal stem cells seeded onto bioscaffolds. Carcinogenesis 2009;30:150-157.

-17 Bi Y, Ehirchiou D, Kilts TM, Inkson CA, Embree MC, Sonoyama W, Li L, Leet AI, Seo BM, Zhang L, Shi S, Young MF: Identification of tendon stem/progenitor cells and the role of the extracellular matrix in their niche. Nat Med 2007;13:1219-1227.

-18 Rui YF, Lui PP, Li G, Fu SC, Lee YW, Chan KM: Isolation and characterization of multipotent rat tendonderived stem cells. Tissue Eng Part A 2010;16:1549-1558. 


\section{Cellular Physiology and Biochemistry}

Cell Physiol Biochem 2014;34:2153-2168

\begin{tabular}{l|l}
\hline DOI: $10.1159 / 000369659$ & (c) 2014 S. Karger AG, Basel
\end{tabular}

\begin{tabular}{l|l} 
Publisned onine: December 02, 2014 & www.karger.com/cpb
\end{tabular}

Chen et al.: TDSCs Promote PRP Induced Healing in Achilles Tendinopathy

19 Zhang J, Wang JH: Characterization of differential properties of rabbit tendon stem cells and tenocytes. BMC Musculoskelet Disord 2010;11:10.

20 Lovati AB, Corradetti B, Lange Consiglio A, Recordati C, Bonacina E, Bizzaro D, Cremonesi F: Characterization and differentiation of equine tendon-derived progenitor cells. J Biol Regul Homeost Agents 2011;25:S75-84.

21 Chen L, Dong SW, Tao X, Liu JP, Tang KL, Xu JZ: Autologous platelet-rich clot releasate stimulates proliferation and inhibits differentiation of adult rat tendon stem cells towards nontenocyte lineages. J Int Med Res 2012;40:1399-1409.

-22 Ni M, Lui PP, Rui YF, Lee YW, Lee YW, Tan Q, Wong YM, Kong SK, Lau PM, Li G, Chan KM: Tendon-derived stem cells (tdscs) promote tendon repair in a rat patellar tendon window defect model. J Orthop Res 2012;30:613-619.

23 Marx RE: Platelet-rich plasma (prp): What is prp and what is not prp? Implant Dent 2001;10:225-228.

24 Spaas JH, Guest DJ, Van de Walle GR: Tendon regeneration in human and equine athletes: Ubi sumus-quo vadimus (where are we and where are we going to)? Sports Med 2012;42:871-890.

25 Dahlgren LA, Mohammed HO, Nixon AJ: Temporal expression of growth factors and matrix molecules in healing tendon lesions. J Orthop Res 2005;23:84-92.

-26 Tsubone T, Moran SL, Amadio PC, Zhao C, An KN: Expression of growth factors in canine flexor tendon after laceration in vivo. Ann Plast Surg 2004;53:393-397.

27 de Mos M, van der Windt AE, Jahr H, van Schie HT, Weinans H, Verhaar JA, van Osch GJ: Can platelet-rich plasma enhance tendon repair? A cell culture study. Am J Sports Med 2008;36:1171-1178.

28 Visser LC, Arnoczky SP, Caballero 0, Kern A, Ratcliffe A, Gardner KL: Growth factor-rich plasma increases tendon cell proliferation and matrix synthesis on a synthetic scaffold: An in vitro study. Tissue Eng Part A 2010;16:1021-1029.

29 Zhang J, Wang JH: Platelet-rich plasma releasate promotes differentiation of tendon stem cells into active tenocytes. Am J Sports Med 2010;38:2477-2486.

30 Fleming BC, Spindler KP, Palmer MP, Magarian EM, Murray MM: Collagen-platelet composites improve the biomechanical properties of healing anterior cruciate ligament grafts in a porcine model. Am J Sports Med 2009;37:1554-1563.

-31 Mishra A, Pavelko T: Treatment of chronic elbow tendinosis with buffered platelet-rich plasma. Am J Sports Med 2006;34:1774-1778.

32 Randelli PS, Arrigoni P, Cabitza P, Volpi P, Maffulli N: Autologous platelet rich plasma for arthroscopic rotator cuff repair. A pilot study. Disabil Rehabil 2008;30:1584-1589.

-33 Sanchez M, Anitua E, Azofra J, Andia I, Padilla S, Mujika I: Comparison of surgically repaired achilles tendon tears using platelet-rich fibrin matrices. Am J Sports Med 2007;35:245-251.

-34 Peerbooms JC, Sluimer J, Bruijn DJ, Gosens T: Positive effect of an autologous platelet concentrate in lateral epicondylitis in a double-blind randomized controlled trial: Platelet-rich plasma versus corticosteroid injection with a 1-year follow-up. Am J Sports Med 2010;38:255-262.

35 Andres BM, Murrell GA: Treatment of tendinopathy: What works, what does not, and what is on the horizon. Clin Orthop Relat Res 2008;466:1539-1554.

-36 Coombes BK, Bisset L, Vicenzino B: Efficacy and safety of corticosteroid injections and other injections for management of tendinopathy: A systematic review of randomised controlled trials. Lancet 2010;376:17511767.

-37 de Vos RJ, Weir A, van Schie HT, Bierma-Zeinstra SM, Verhaar JA, Weinans H, Tol JL: Platelet-rich plasma injection for chronic achilles tendinopathy: A randomized controlled trial. JAMA 2010;303:144-149.

- 38 de Vos RJ, Windt J, Weir A: Strong evidence against platelet-rich plasma injections for chronic lateral epicondylar tendinopathy: A systematic review. Br J Sports Med 2014;48:952-956.

-39 Schweitzer R, Chyung JH, Murtaugh LC, Brent AE, Rosen V, Olson EN, Lassar A, Tabin CJ: Analysis of the tendon cell fate using scleraxis, a specific marker for tendons and ligaments. Development 2001;128:38553866.

40 Rui YF, Lui PP, Wong YM, Tan Q, Chan KM: Bmp-2 stimulated non-tenogenic differentiation and promoted proteoglycan deposition of tendon-derived stem cells (tdscs) in vitro. J Orthop Res 2013;31:746-753.

41 Xu B, Song G, Ju Y: Effect of focal adhesion kinase on the regulation of realignment and tenogenic differentiation of human mesenchymal stem cells by mechanical stretch. Connect Tissue Res 2011;52:373379. 


\section{Cellular Physiology and Biochemistry}

Cell Physiol Biochem 2014;34:2153-2168

\begin{tabular}{l|l}
\hline DOI: $10.1159 / 000369659$ & (c) 2014 S. Karger AG, Basel
\end{tabular}

Chen et al:: TDSCs Promote PRP Induced Healing in Achilles Tendinopathy

42 Xu B, Song G, Ju Y, Li X, Song Y, Watanabe S: Rhoa/rock, cytoskeletal dynamics, and focal adhesion kinase are required for mechanical stretch-induced tenogenic differentiation of human mesenchymal stem cells. J Cell Physiol 2012;227:2722-2729.

43 Hoffmann A, Pelled G, Turgeman G, Eberle P, Zilberman Y, Shinar H, Keinan-Adamsky K, Winkel A, Shahab S, Navon G, Gross G, Gazit D: Neotendon formation induced by manipulation of the smad8 signalling pathway in mesenchymal stem cells. J Clin Invest 2006;116:940-952.

44 Lui PP, Fu SC, Chan LS, Hung LK, Chan KM: Chondrocyte phenotype and ectopic ossification in collagenaseinduced tendon degeneration. J Histochem Cytochem 2009;57:91-100.

-45 Chen L, Dong SW, Liu JP, Tao X, Tang KL, Xu JZ: Synergy of tendon stem cells and platelet-rich plasma in tendon healing. J Orthop Res 2012;30:991-997.

-46 Kajikawa Y, Morihara T, Sakamoto H, Matsuda K, Oshima Y, Yoshida A, Nagae M, Arai Y, Kawata M, Kubo T: Platelet-rich plasma enhances the initial mobilization of circulation-derived cells for tendon healing. J Cell Physiol 2008;215:837-845.

47 Chen J, Yu Q Wu B, Lin Z, Pavlos NJ, Xu J, Ouyang H, Wang A, Zheng MH: Autologous tenocyte therapy for experimental achilles tendinopathy in a rabbit model. Tissue Eng Part A 2011;17:2037-2048.

48 Lui PP, Chan LS, Fu SC, Chan KM: Expression of sensory neuropeptides in tendon is associated with failed healing and activity-related tendon pain in collagenase-induced tendon injury. Am J Sports Med 2010;38:757-764.

-49 Movin T, Gad A, Reinholt FP, Rolf C: Tendon pathology in long-standing achillodynia. Biopsy findings in 40 patients. Acta Orthop Scand 1997;68:170-175.

50 Amstutz HC, Coulson WF, David E: Reconstruction of the canine achilles and patellar tendons using dacron mesh silicone prosthesis. I. Clinical and biocompatibility evaluation. J Biomed Mater Res 1976;10:47-59.

51 Badylak SF, Tullius R, Kokini K, Shelbourne KD, Klootwyk T, Voytik SL, Kraine MR, Simmons C: The use of xenogeneic small intestinal submucosa as a biomaterial for achilles tendon repair in a dog model. J Biomed Mater Res 1995;29:977-985.

52 Bolt P, Clerk AN, Luu HH, Kang Q Kummer JL, Deng ZL, Olson K, Primus F, Montag AG, He TC, Haydon RC, Toolan BC: Bmp-14 gene therapy increases tendon tensile strength in a rat model of achilles tendon injury. J Bone Joint Surg Am 2007;89:1315-1320.

-53 Chen YJ, Wang CJ, Yang KD, Kuo YR, Huang HC, Huang YT, Sun YC, Wang FS: Extracorporeal shock waves promote healing of collagenase-induced achilles tendinitis and increase tgf-beta1 and igf-i expression. J Orthop Res 2004;22:854-861.

54 Dallaudiere B, Lempicki M, Pesquer L, Louedec L, Preux PM, Meyer P, Hummel V, Larbi A, Deschamps L, Journe C, Hess A, Silvestre A, Sargos P, Loriaut P, Boyer P, Schouman-Claeys E, Michel JB, Serfaty JM: Efficacy of intra-tendinous injection of platelet-rich plasma in treating tendinosis: Comprehensive assessment of a rat model. Eur Radiol 2013;23:2830-2837.

55 Hsu C, Chang J: Clinical implications of growth factors in flexor tendon wound healing. J Hand Surg Am 2004;29:551-563.

56 Molloy T, Wang Y, Murrell G: The roles of growth factors in tendon and ligament healing. Sports Med 2003;33:381-394.

57 Wang JH: Mechanobiology of tendon. J Biomech 2006;39:1563-1582.

-58 Anitua E, Andia I, Sanchez M, Azofra J, del Mar Zalduendo M, de la Fuente M, Nurden P, Nurden AT: Autologous preparations rich in growth factors promote proliferation and induce vegf and hgf production by human tendon cells in culture. J Orthop Res 2005;23:281-286. 